\title{
Mineral Tannages
}

\author{
By F. L. Seymour-Jones ${ }^{1}$
}

Columbia University, New York, N. Y.

A MONG the various mineral tannages that of chrome continues to hold pride of place. Two methods are in general use. In the one-bath process the skins are treated in a solution of a basic chromic salt, usually chrome alum with soda, or bichromate reduced to the chromic state. This is followed by neutralization of the excess of free acid with a suitable weak alkali. In the two-bath process the skins are treated first in a liquor of bichromate and hydrochloric acid, then passed to a reducing bath of acid and sodium thiosulfate. Most of the recent scientific work has been concerned with the one-bath process.

One-Bath Chrome Liovors

Acidity and Neutral Salts-The attainment of a correct basicity is important in the one-bath method. With very basic liquors tannage is extremely slow. With only slightly basic liquors the skins are abnormally plumped by the acid from the salt hydrolysis, and the resulting leather is poor. As the basicity of a chrome liquor is increased a point is reached where the chromium begins to precipitate out. When neutral salts are present in the liquor more alkali is

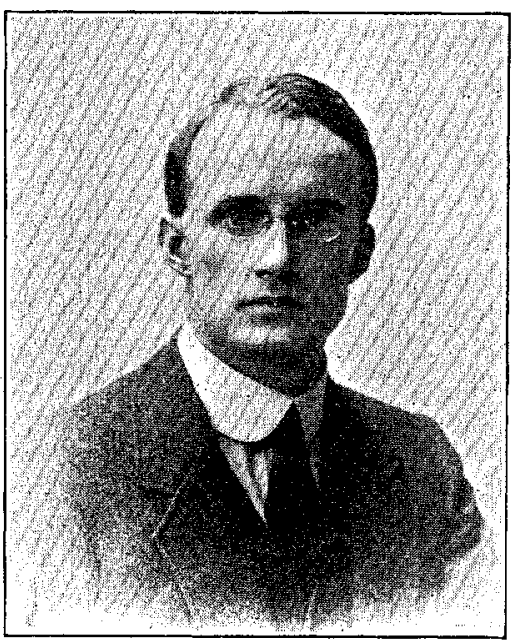

F. L. SEYMOUR-JONES cept at concentrations greater than $3 M$, hydration seems of secondary importance, and they suggest that the chief factor is the formation of addition compounds. Burton ${ }^{9}$ earlier considered double salt formation to be of slight importance.

Wilson and Gallun ${ }^{10}$ find that the addition of chlorides retards tanning to an extent depending on their concentration. Magnesium chloride is anomalous, the greatest retardation occurring at about molar concentration. Burton and Glover, ${ }^{11}$ using gelatin, find that the amount of chromium adsorbed varies with the degree of hydration of the neutral salt; chlorides increase and sulfates decrease the amount of acid taken up. In working on pelt ${ }^{12}$ they find that chlorides retard tannage to a greater degree than sulfates. 'Burton' considers that neutral salts in chromium sulfate liquors tend to form acid sulfates. The equilibrium is thus changed and more basic chromium salts are formed with sulfates added than with chlorides.

The work on acidity and neutral salts demonstrates conclusively that difficulties will arise in practice if a chrome liquor is judged solely by its basicity and chrorequired to bring about incipient precipitation. Wilson and Kern ${ }^{2}$ connected this effect with the hydration of the neutral salt in solution. Thomas and Baldwin ${ }^{3}$ found no connection between basicity as usually expressed and the true acidity determined with the hydrogen electrode. The acidity of chrome liquors decreases with dilution and with the time of standing. They also found ${ }^{4}$ that the addition of chlorides to chromium sulfate solutions invariably increases the hydrion concentration, while sulfates at first decrease it and only increase it again at high concentrations. With sulfuric acid, chlorides increase and sulfates decrease the hydrion concentration. By adding chlorides to chromic chloride solutions Baldwin ${ }^{5}$ again found the acidity increased. The addition of neutral salts to chrome liquors was shown by Thomas and Baldwin ${ }^{6}$ to give a rapid increase in acidity, followed by a slow decrease. Chlorides increase and sulfates decrease the hydrion concentration of sulfuric and hydrochloric acids. Magnesium sulfate behaves irregularly, decreasing the hydrion concentration up to $0.8 M$, but increasing it thereafter. Wilson ${ }^{7}$ has shown that for chlorides this effect can be explained by the hydration of the salts in solution, but this cannot hold for sulfates, which decrease acidity. Hence, Thomas and Foster ${ }^{8}$ extended this work, using sodium chloride and sulfate, and sucrose, the latter being chosen as a hydrating nonelectrolyte. Since sucrose did not retard tanning ex-

1 Goldschmidt Fellow of Columbia University 1921-2; 1851 Exhibition Scholar of the University of Leeds.

$2 J$. Am. Leather Chem. Assoc., 12 (1917), 445.

Ibid., 18 (1918), 192.

Ibid., 13 (1918), 248.

Ibid., 14 (1919), 10.

- J. Am. Chem. Soc., 41 (1919), 1981.

Ibid, $42(1920), 715$.

- Ters JotrnaI, 14 (1922), 132. mium content. The presence of neutral salts and the age and dilution of the liquor must also be taken into account. Further light on the exact mechanism of these effects is likely to come from a study of chromium salts and solutions from the viewpoint of inorganic, physical, and colloidal chemistry.

Conchntration EFFECTs-The effect of concentration of chrome liquor on the adsorption of its constituents by hide powder has been studied by Baldwin ${ }^{14}$ and by Thomas and Kelly. ${ }^{15}$ The fixation of chromium by the hide powder rises rapidly to a maximum at a concentration of $1.6 \mathrm{~g}$. of chromic oxide per $100 \mathrm{cc}$., then falls to a minimum at a concentration of $14.75 \mathrm{~g}$. per $100 \mathrm{cc}$., at which it remains constant up to $20.2 \mathrm{~g}$. per $100 \mathrm{cc}$., the limiting value examined. The hydrogen-ion concentration for this was $0.006 M$. These figures were obtained by analysis of the tanned powder. If the residual liquor is analyzed, at the higher concentrations "negative adsorption" occurs, $i$. e., more water than chromic oxide is absorbed. The figures so obtained furnish an interesting example of the danger of determining adsorption by analysis of the residual liquor, a method implying total neglect of the role played by the solvent.

TIMn EFfECTs-The effect of varying time on the fixation of chromium by hide powder has been studied over wide ranges of time and concentration by Thomas, Baldwin, and Kelly, ${ }^{18}$ and by Thomas and Kelly. ${ }^{17}$ Taking 750 as

- J. Soc. Leather Trades' Chem., 5 (1921), 187.

$10 \mathrm{~J}$. Am. Leather Chem. Assoc., 16 (1920), 273.

11 J. Soc. Leather Trades' Chem., 6 (1921), 183, 187.

12 Ibid., 6 (1922), 6.

is Ibid., 5 (1921), 192.

$14 J . A m$. Leather Chem. Assoc., 14 (1919), 433

15 This Journal, 13 (1921), 31.

16 J. Am. Leather Chem. Assoc., is (1920), 147.

17 Ibid., 15 (1920), 487; ThIS JOURNAL, 14 (1922), 621. 
the combining weight of collagen, on the basis of it being the anhydride of gelatin, Wilson ${ }^{18}$ points out that for every 100 g. of collagen at least $3.38 \mathrm{~g}$. of chromic oxide are necessarily fixed to produce a chromium collagenate. Thomas, Baldwin and Kelly, plotting concentration of liquor against the amount of chromic oxide fixed by $100 \mathrm{~g}$. of collagen, find sharp maxima, depending on the time but at the same concentration, at amounts of chromic oxide exactly four and eight times $3.38 \mathrm{~g}$., thus pointing to the formation of a tetrachrome and an octachrome collagen. 'The octachrome curve also shows a point of inflexion, at a higher concentration of liquor, corresponding to a tetrachrome collagen. Even if these results do not definitely prove the formation of a chemical compound, they are of great significance and must be taken into account in any theory of chrome tanning. The work certainly supports the theory of a chemical combination of the chromium and the hide substance.

Vrolet and Green Chrome Solutions-Chromic salts in solution are violet in the cold and green when hot, ordinary solutions being an equilibrium mixture. Two-thirds of the acid radical forms part of the cation in green solution, while in the violet all three chloride ions (in chromic chloride) are anions. The green solutions are far more hydrolyzed, and Blockey ${ }^{19}$ showed that in green chrome alum solutions the hydrion concentration is ten times that in the violet. Burton $^{20}$ found that violet solutions tan more rapidly than green, which he attributed to the different acidity. Griliches ${ }^{21}$ found no difference in the tanning action of green and violet liquors, but his theories of the mechanism of chrome tanning have been severely criticized by Stiasny. ${ }^{22}$

One curious phenomenon in the varying amounts of sodium hydroxide and carbonate necessary to bring about a permanent precipitate in a chrome liquor has been studied by Burton. ${ }^{23}$ It is best shown by Burton's figures.

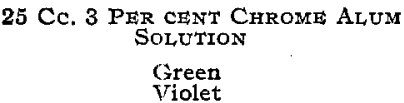

That green solutions should require more sodium hydroxide than violet is to be expected in view of their greater acidity, but why the reverse should be true with sodium carbonate is not clear. Burton attributes it to the liberated carbon dioxide functioning as a stabilizing acid in solution, and the more asid green liquors driving more carbon dioxide from solution.

Meunier and Caste ${ }^{24}$ with chrome alum solutions found the amounts of sodium carbonate necessary to start precipitation to be proportional to the chromium concentration at $0^{\circ}$, but to increase more rapidly than the chromium concentration at $100^{\circ}$. The amount of soda required decreases on stirring and on heating, due to the liberation of carbon dioxide and the polymerization of basic chrome salts. On aging chrome solutions the amount of soda required at first rapidly increases, then slowly diminishes to a very low value. From old or hot solutions a basic sulfate is precipitated and from fresh or cold solutions, chromium hydroxide.

Burton $^{25}$ has recently reviewed the problems of one-bath chrome tanning, and gives an extensive bibliography.

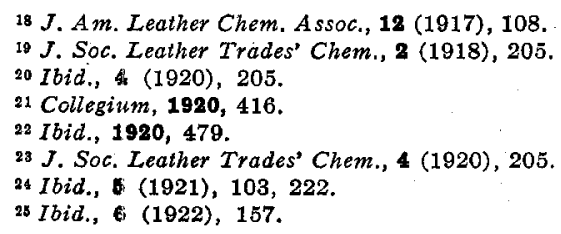

\section{Two-Bath Chrome Lieuors}

Little work has been done on the two-bath tannage. Innes ${ }^{26}$ studied the bleeding of leather from the first (acidbichromate) bath. He found that most of the chromium which diffuses out is reabsorbed by the skin, and that under certain conditions bleeding is not a serious phenomenon. Schorlemmer ${ }^{27}$ points out the disadvantage of even traces of arsenic ( 0.0015 per cent) in the second (acid-thiosulfate) bath, and advances a theory that the reactions of the second bath are:

$$
\begin{aligned}
& \mathrm{Na}_{2} \mathrm{~S}_{2} \mathrm{O}_{3}+2 \mathrm{HCl} \longrightarrow 2 \mathrm{NaCl}+\mathrm{H}_{2} \mathrm{SO}_{3}+\mathrm{S} \\
& 5 \mathrm{Na}_{2} \mathrm{~S}_{2} \mathrm{O}_{3}+6 \mathrm{HCl} \longrightarrow 2 \mathrm{Na}_{2} \mathrm{~S}_{5} \mathrm{O}_{6}+6 \mathrm{NaCl}+3 \mathrm{H}_{2} \mathrm{O}
\end{aligned}
$$

Arsenic catalyzes the second reaction, and thus impedes or prevents reduction. This view of the reactions is not in accord with the earlier work of Stiasny and Das, ${ }^{28}$ which has met with general acceptance.

\section{Miscellaneous Chrome Processes}

Cross, Greenwood, and Lamb ${ }^{29}$ have patented the use of concentrated solutions of chrome salts in gum tragasol jellies for rapid tanning, and Turnbull and Carmichael ${ }^{30}$ patented starch for the same purpose. While effective and rapid, the process is messy in use, and the jelly material awkward in the drainage channels and pipes. Lamb ${ }^{31}$ has patented the use of salts of hydroxy organic acids for stripping chrome leather scraps for glue stock, but this action of such salts in removing chromium from leather (and preventing its proper tannage in chrome liquors) had previously been demonstrated by Procter and Wilson. ${ }^{32}$

\section{Theory of Chrome Tannage}

The theory of chrome tannage is still obscure. Wilson ${ }^{33}$ considers that the collagen first combines with a basic chrome salt through a single valence of the chromium atom. Further hydrolysis of the chromium compound then takes place and a second valence of the chromium unites with the collagen. Still more slowly the third valence unites with the collagen, and chromium collagenate is formed. Meunier ${ }^{34}$ prefers to regard chrome tanning as a slow and irreversible adsorption of colloidal chromic oxide with the precipitation of a gel on the fibril surfaces, followed by a slow penetration of the gel into the interior of the fibrils.

\section{Iron Tannage}

Iron tannage is still in the early experimental stage. Pres- . sure of war conditions forced the Germans to adopt it to some extent, and it has met with its greatest application when combined with other tannages, chrome, formaldehyde, and vegetable. Most of the work so far is embodied in the many patents which have been taken out in this connection, particularly by $\mathrm{O}$. Röhm in Germany. Casaburi, ${ }^{35}$ and Jackson and $\mathrm{Hou}^{36}$ have described their work on straight iron tannage and have shown the question of basicity to be of great importance. The keeping qualities of the leather have yet to be demonstrated.

26 J. Soc. Leather Trades' Chem., 3 (1919), 104.

27 Collegium, 1921, 430.

$28 \mathrm{~J}$. Soc. Chem. Ind., 31 (1921), 753.

29 J. Soc. Dyers Col., 35 (1919), 62.

80 Brit. Patent 110,470 .

81 Brit. Patent 132,864.

32 J. Soc. Chem. Ind., 35 (1916), 156

33 Private communication; cf. J. Am. Leather Chem. Assoc., 12 (1917),

108, and the theory of alum tanning therein described.

34 Chimie et industrie, 1 (1918), 71, 272.

85 J. Soc. Leather Trades' Chem., 8 (1919), 61, 74

si J. Am. Leather Chem. Assoc., 16 (1921), 63, 139, 202, 229. 